Original article

\title{
Correlations of sensory parameters with physicochemical characteristics of Argentinean honeys by multivariate statistical techniques
}

\author{
Mariela Patrignani, ${ }^{1}$ Maria Cristina Ciappini, ${ }^{2}$ Chrysoula Tananaki, ${ }^{3}$ Guillermina Andrea Fagúndez, \\ Andreas Thrasyvoulou ${ }^{3} \&$ Cecilia Elena Lupano ${ }^{1 *}$ iD \\ 1 Centro de Investigación y Desarrollo en Criotecnología de Alimentos (CIDCA), Facultad de Ciencias Exactas, UNLP - CCT La Plata - \\ CONICET- CIC, 47 and 116, 1900 La Plata, Argentina \\ 2 CIDTA, Facultad Regional Rosario, Universidad Tecnológica Nacional, E. Zeballos 1341, 2000 Rosario, Santa Fe, Argentina \\ 3 Laboratory of Apiculture-Sericulture, School of Agriculture, Faculty of Agriculture, Forestry and Natural Environmental, Aristotle \\ University, Aristotle University Farm, Thermi-Thessaloniki, PC 5700, Greece \\ 4 Laboratorio de Actuopalinología, Centro de Investigaciones Científicas y Transferencia Tecnológica a la Producción (CICyTTP - \\ CONICET) - Facultad de Ciencia y Tecnología, (FCyT - UADER), Materi y España, E3105BWA, Diamante, Entre Ríos, Argentina
}

(Received 8 September 2017; Accepted in revised form 12 November 2017)

Summary Honey acceptability is mainly determined by its colour, crystallisation degree and aroma. In the present work, the sensory characteristics and physicochemical parameters of Argentinean honeys from different ecoregions were analysed. Moisture content, Pfund colour, diastase activity, hydroxymethylfurfural content, electrical conductivity, sugar profile and volatile compounds were analytically determined in honey samples, while sensory characteristics (crystal size, fluency score, sweetness, persistence, granularity, crystallisation, colour intensity and aroma) were evaluated by a trained panel. Significant correlations were found between honey crystallisation degree and hydroxymethylfurfural content and diastase activity $(P \leq 0.05)$. It could be confirmed that honey crystallisation interferes with the visual perception of colour. Floral, fresh fruit, ripe fruit, balsamic and wood aromas could be successfully linked to honey volatile profile $(P \leq 0.05)$. These results demonstrate that the parameters that could best guarantee the consumers' preference can be successfully associated with the chemical composition of honey by multivariate statistical analysis.

Keywords Aroma, colour, crystallisation, honey, multivariate analysis, sensory analysis, volatile compounds.

\section{Introduction}

Honey is a well-accepted aromatic natural product with a distinctive flavour. It is mainly composed of carbohydrates $(60 \%-85 \%)$ water $(12 \%-23 \%)$ and some other minor components (Machado De-Melo et al., 2017). Moreover, honey is considered an important source of antioxidants with significant benefits for health, mostly related to the presence of phenolic compounds (especially flavonoids) (Patrignani et al., 2015; Castiglioni et al., 2017). On the other hand, other products such as propolis and bee pollen have also shown beneficial effects. Boufadi et al. (2016) concluded that propolis extracts presented high antimicrobial activity, while Zhao et al., 2017 have indicated

*Correspondent: Fax: +54 221425 4853;

e-mail: cel@quimica.unlp.edu.ar that bee pollen could be considered a potential functional food.

Chemical composition and botanical origin of honey define its sensory characteristics and acceptability. Therefore, an accurate understanding of the correlations between its sensory and physicochemical characteristics is a fundamental issue to establish the parameters that could best guarantee the quality of this product. The present work focuses on three honey characteristics that strongly define its acceptability and buying intention of consumers: aroma, colour and crystallisation degree (Belay et al., 2015; Brščić et al., 2017).

Argentina is the second largest honey exporter after China, and the quality of its products is recognised worldwide (Patrignani et al., 2015). Nevertheless, honey is mainly sold in bulk without any floral 
classification, and there is only limited information on its sensory characteristics (Ciappini et al., 2016). Besides, the association between the physicochemical characterisation of Argentinean honeys and their flavour and texture parameters remains unstudied.

Therefore, the goal of the present work was to contribute to the understanding of the complex world of honey flavour and acceptability. Hence, a complete description of several physicochemical parameters and sensory characteristics was performed, and their correlations were analysed in detail.

\section{Material and methods}

\section{Honey collection}

A total of 25 honey samples harvested in 2014 from four different ecoregions of Argentina were collected directly from producers (six honey samples from Pampa, six samples from Parana Delta and Islands, six samples from Espinal and seven from Patagonian Forest (Fig. S1). Pampa, Parana Delta and Islands, and Espinal ecoregions are located in Buenos Aires province, the most important apicultural region of Argentina (Patrignani et al., 2015). Patagonian forest is located in the southwest of Argentina; although it is not an important apicultural region, it lacks human intervention and offers possibilities for a contamination-free apiculture industry (Forcone, 2008).

Sensory determinations were performed immediately after obtaining the honey samples. Then, samples were stored in the dark at $-20{ }^{\circ} \mathrm{C}$ until physicochemical analysis.

\section{Analytical determinations}

Diastase activity after Schade, hydroxymethylfurfural (HMF) content after White, moisture (refractometric method), electrical conductivity and sugars (fructose, glucose, sucrose, turanose, maltose, trehalose, melezitose, melibiose and raffinose) by HPLC were analysed in accordance with Bogdanov (2002).

\section{Colour measurement}

Honey colour was measured on the Pfund scale (mmPfund) using a photometer with direct read-out (HANNA HI-8322 honey colour analyser, Romania).

\section{Volatile compound analysis}

Each honey sample (10 g) was accurately weighed and diluted with $10 \mathrm{~g}$ of pure water. Then, $15 \mu \mathrm{L}$ of the internal standard styrene solution $\left(10 \mu \mathrm{g} \mathrm{mL}^{-1}\right.$ in acetone) was added. The extraction, separation and characterisation of volatile compounds were performed in accordance with Tananaki et al. (2007). Samples were heated at $40{ }^{\circ} \mathrm{C}$ and directly purged with helium gas $\left(30 \mathrm{~mL} \mathrm{~min}{ }^{-1}\right)$ during $30 \mathrm{~min}$ (purge and trap system O.I. Analytical, 4552). The volatile compounds were collected on a sample concentrator OI Analytical 4560. Then, the trapped compounds were desorbed by raising the trap temperature at $180{ }^{\circ} \mathrm{C}$ for $7 \mathrm{~min}$. The isolated compounds were separated with an Agilent Model 6980 gas chromatograph, coupled with an Agilent 5973 mass detector (electron impact mass spectra $70 \mathrm{eV}$ ). Separation was performed on a capillary column SGE BPX5 $(30 . \mathrm{m} / 0.25 \mathrm{~mm} / 0.25 \mu \mathrm{m})$. Oven temperature is as follows: $40{ }^{\circ} \mathrm{C}$ for $5 \mathrm{~min}$, then to $55^{\circ} \mathrm{C}$ at $1{ }^{\circ} \mathrm{C} \mathrm{min}{ }^{-1}$, to $120{ }^{\circ} \mathrm{C}$ at $3{ }^{\circ} \mathrm{C} \mathrm{min}^{-1}$, to $230{ }^{\circ} \mathrm{C}$ at $10{ }^{\circ} \mathrm{C} \mathrm{min}{ }^{-1}$ and to $280{ }^{\circ} \mathrm{C}$ at $20{ }^{\circ} \mathrm{C} \mathrm{min}{ }^{-1}$. This temperature was held for 5 min (injector temperature: $220^{\circ} \mathrm{C}$ ). Helium was used as the carrier gas (flow

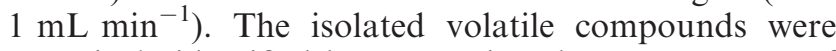
tentatively identified by comparing the mass spectra of unknown peaks with those stored in the National Institute of Standards and Technology (NIST) library with a similarity threshold higher than $75 \%$. The relative concentration of each isolated compound was calculated as the relative peak area, by dividing the peak area of the isolated volatile compound by the peak area of styrene (Silva et al., 2017).

\section{Sensory analysis}

A panel of 12 highly qualified assessors selected and trained following IRAM standards (IRAM 20005-1: 1996) evaluated the odour, appearance and colour of honey, as described in IRAM 15980-1:2014 and IRAM, 19962: 1995. Briefly, the colour intensity, sweetness, salty, sour and bitter taste, persistency as well as several parameters associated with the crystallisation of honey samples (the scale of granularity, fluency, crystallisation and crystal size) were determined on a seven-point scale, where zero indicated no property (Ciappini et al., 2016). The 'granularity' parameter was related to the perception of the crystal size and number in the mouth, whereas 'crystallisation' refers to the presence of crystals. Finally 'fluency' and 'crystal size' were appearance parameters visually evaluated (Ciappini et al., 2013).

Aroma attributes were grouped into odour families, as recommended by Piana et al. (2004) with slight modifications (Ciappini et al., 2013; IRAM 159801:2014). Panellists had to select the descriptors they considered appropriate from a list of pre-established words that define honey aroma (Table S1).

\section{Pollen analysis}

The pollen content was analysed according to Louveaux et al. (1978). 


\section{Statistical analysis}

The statistical differences of the analytical determinations were obtained through an analysis of variance (ANOVA) followed by Fisher's test at 95\% confidence level $(P \leq 0.05)$.

The sensory analysis results were processed using multivariate statistical techniques involving principal component analysis (PCA), correspondence analysis (CA) and canonical correspondence analysis (CCA) (CANOCO 5, Biometris, Netherlands). Prior to these analyses, data were standardised and centred.

PCA was performed in order to find similarities between the honey samples according to their sensory parameters. In this way, it was possible to recognise different sets of honey samples characterised by their odour intensity, sweetness, persistency and the parameters associated with their crystallisation. PCA reduces the dimensionality of the data set by transforming it into a new set of variables (the principal components) without losing much information (Patrignani et al., 2015). A high absolute value of a standardised variable indicates an important contribution to the principal component (Truzzi et al., 2014). According to the Kaiser's criterion, only principal components with eigenvalues $>1$ should be considered in the analysis (Grane \& Jach, 2014). These values indicate the importance measure of an ordination axis (Braak \& Smilauer, 2012). To evaluate the linear correlations between sensory parameters and psychochemical characteristics, Pearson's coefficients were calculated.

To obtain a suitable description of the odours that best described the honey samples, CA was performed. $\mathrm{CA}$ is a generalised PCA recommended for the analysis of qualitative data (Valentin et al., 2012) that offers a visualisation of the similarities between products, between descriptors and the associations between products and descriptors (Kostov et al., 2014).

Table 1 Mean and standard deviation of physicochemical parameters and sugar content of Argentinean honeys

\begin{tabular}{|c|c|c|c|c|c|}
\hline & $\mathbf{P}($ anova $) *$ & $\begin{array}{l}\text { Patagonian } \\
\text { Forest }(n=7)\end{array}$ & Espinal $(n=6)$ & Pampa $(n=6)$ & $\begin{array}{l}\text { Parana Delta and } \\
\text { Islands }(n=6)\end{array}$ \\
\hline $\mathrm{HMF}\left(\mathrm{mg} \mathrm{kg}^{-1}\right)$ & 0.157 & $3.27 \pm 4.86^{\mathrm{a}}$ & $5.89 \pm 2.68^{a}$ & $15.47 \pm 13.10^{a}$ & $24.7 \pm 32.54^{\mathrm{a}}$ \\
\hline Diastase activity & 0.096 & $21.13 \pm 5.48^{a}$ & $29.58 \pm 6.31^{\mathrm{a}}$ & $24.77 \pm 4.72^{\mathrm{a}}$ & $23.8 \pm 8.46^{\mathrm{a}}$ \\
\hline Conductivity ( $\left.\mathrm{mS} \mathrm{cm}^{-1}\right)$ & 0.001 & $0.66 \pm 0.27^{\mathrm{b}}$ & $0.38 \pm 0.4^{\mathrm{a}}$ & $0.23 \pm 0.09^{a}$ & $0.4 \pm 0.05^{a}$ \\
\hline Pfund colour (mmPfund) & $<0.001$ & $69.13 \pm 20.27^{b}$ & $58.17 \pm 25.10^{b}$ & $28 \pm 8.17^{a}$ & $73.67 \pm 17.40^{b}$ \\
\hline Fructose $(\mathrm{g} / 100 \mathrm{~g})$ & 0.094 & $34.34 \pm 1.90^{\mathrm{a}}$ & $35.56 \pm 1.92^{a}$ & $35.11 \pm 0.78^{a}$ & $36.87 \pm 2.15^{a}$ \\
\hline Glucose $(\mathrm{g} / 100 \mathrm{~g})$ & 0.067 & $25.69 \pm 2.30^{a}$ & $27.53 \pm 2.37^{a}$ & $27.28 \pm 0.42^{\mathrm{a}}$ & $26.2 \pm 1.34^{\mathrm{a}}$ \\
\hline Sucrose $(g / 100 g)$ & 0.077 & $0.91 \pm 0.43^{\mathrm{a}}$ & $0.19 \pm 0.47^{a}$ & $0.27 \pm 0.42^{\mathrm{a}}$ & $0.53 \pm 0.58^{a}$ \\
\hline Turanose $(\mathrm{g} / 100 \mathrm{~g})$ & 0.672 & $1.12 \pm 0.51^{a}$ & $0.98 \pm 0.46^{\mathrm{a}}$ & $1.03 \pm 0.26^{a}$ & $0.82 \pm 0.1^{\mathrm{a}}$ \\
\hline Maltose (g/100 g) & 0.232 & $1.84 \pm 0.82^{\mathrm{a}}$ & $1.82 \pm 1.00^{\mathrm{a}}$ & $1.28 \pm 0.32^{\mathrm{a}}$ & $1.14 \pm 0.4^{\mathrm{a}}$ \\
\hline Trehalose (g/100 g) & 0.196 & $\mathrm{Nd}$ & $0.17 \pm 0.42^{\mathrm{a}}$ & $0.15 \pm 0.28^{a}$ & $0.47 \pm 0.58^{a}$ \\
\hline Melezitose (g/100 g) & 0.002 & $3.93 \pm 3.62^{b}$ & $\mathrm{Nd}$ & $\mathrm{Nd}$ & $0.88 \pm 1.07^{\mathrm{a}}$ \\
\hline
\end{tabular}

Nd, Not detected.

Different letters within each row indicate significant differences among regions according to Fisher's test $(P \leq 0.05)$.

${ }^{*}$ The statistically significant values $(P \leq 0.05)$ are reported in bold.

Table 2 Pearson's correlation coefficients of the sensory and physicochemical characteristics of honey

\begin{tabular}{|c|c|c|c|c|c|c|c|c|c|c|}
\hline & Conductivity & HMF & $\begin{array}{l}\text { Colour } \\
\text { Pfund }\end{array}$ & $\begin{array}{l}\text { Diastase } \\
\text { activity }\end{array}$ & Fluency & Crystallisation & $\begin{array}{l}\text { Crystal } \\
\text { size }\end{array}$ & Sweetness & Persistency & Granularity \\
\hline Conductivity & 1 & & & & & & & & & \\
\hline HMF & -0.27 & 1 & & & & & & & & \\
\hline Pfund colour & $0.69 *$ & 0.15 & 1 & & & & & & & \\
\hline Diastase activity & -0.31 & $-0.4^{*}$ & -0.24 & 1 & & & & & & \\
\hline Fluency & 0.29 & -0.07 & 0.3 & -0.13 & 1 & & & & & \\
\hline Crystallisation & -0.29 & 0.15 & -0.19 & 0.07 & $-0.96^{*}$ & 1 & & & & \\
\hline Crystal size & 0.35 & 0.18 & 0.34 & $-0.4^{*}$ & $0.58 *$ & $-0.51 *$ & 1 & & & \\
\hline Sweetness & 0.16 & 0.03 & 0.12 & -0.2 & 0.21 & -0.14 & 0.05 & 1 & & \\
\hline Persistency & -0.01 & 0.09 & 0.14 & -0.09 & -0.08 & 0.15 & -0.2 & 0.05 & 1 & \\
\hline Granularity & -0.26 & $0.42 *$ & 0.01 & -0.16 & -0.1 & 0.24 & 0.29 & 0.24 & 0.24 & 1 \\
\hline Colour intensity & $0.47 *$ & 0.3 & $0.86 *$ & -0.28 & $0.51^{*}$ & $-0.4^{*}$ & 0.38 & 0.13 & 0.27 & 0.05 \\
\hline
\end{tabular}

${ }^{*}$ Significant correlation $(P \leq 0.05)$. 
Figure 1 PCA-biplot of sensory analysis of Argentinean honey samples from different ecoregions.

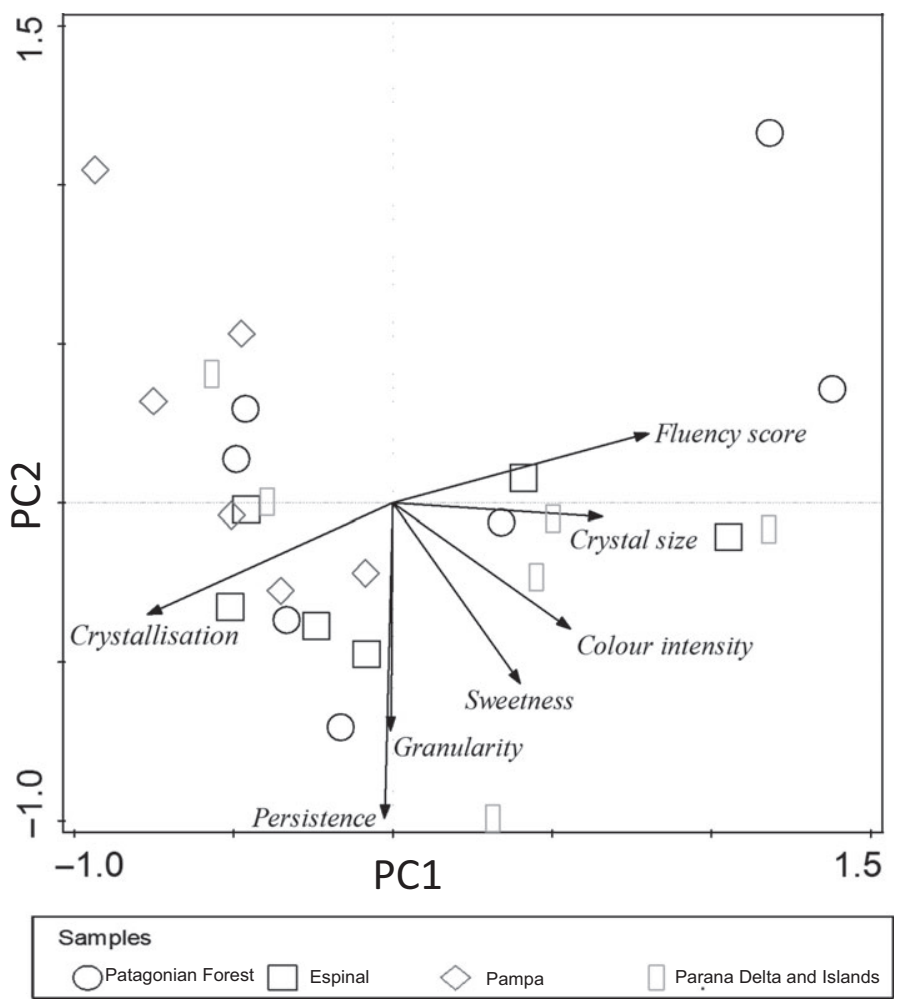

explain the standard deviations observed in the honey parameters (Table 1) (Lichtenberg-Kraag, 2014).

In accordance with the Codex Alimentarius and EU Directive 110/2001, none of the analysed samples exceed the $20 \mathrm{~g} / 100 \mathrm{~g}$ of water content and the diastase activity in all of the samples was higher than the 8 Göthe units required as quality criteria by the Codex Alimentarius (Bogdanov et al., 1999) (Table S2). Table 2 shows Pearson's correlation coefficients of some sensory and physicochemical parameters of honey. As expected, a significant negative correlation $(P \leq 0.05)$ was found between HMF content and diastase activity.

Honey colour may determine its price in the market (da Silva et al., 2016). Honeys from Pampa ecoregion showed the lowest value of Pfund colour $(P \leq 0.05)$ and could be classified as 'light honeys'. Moreover, a significant correlation was found between honey conductivity and Pfund colour (Pearson's correlation coefficient $r=0.69, P \leq 0.05$ ) (Table 2). This could be related to the mineral content of honey samples: a high mineral content leads to a high conductivity in honeys and to darker products (da Silva et al., 2016).

\section{Sugars}

No significant differences were found in fructose, glucose, sucrose, turanose, maltose or trehalose content in 


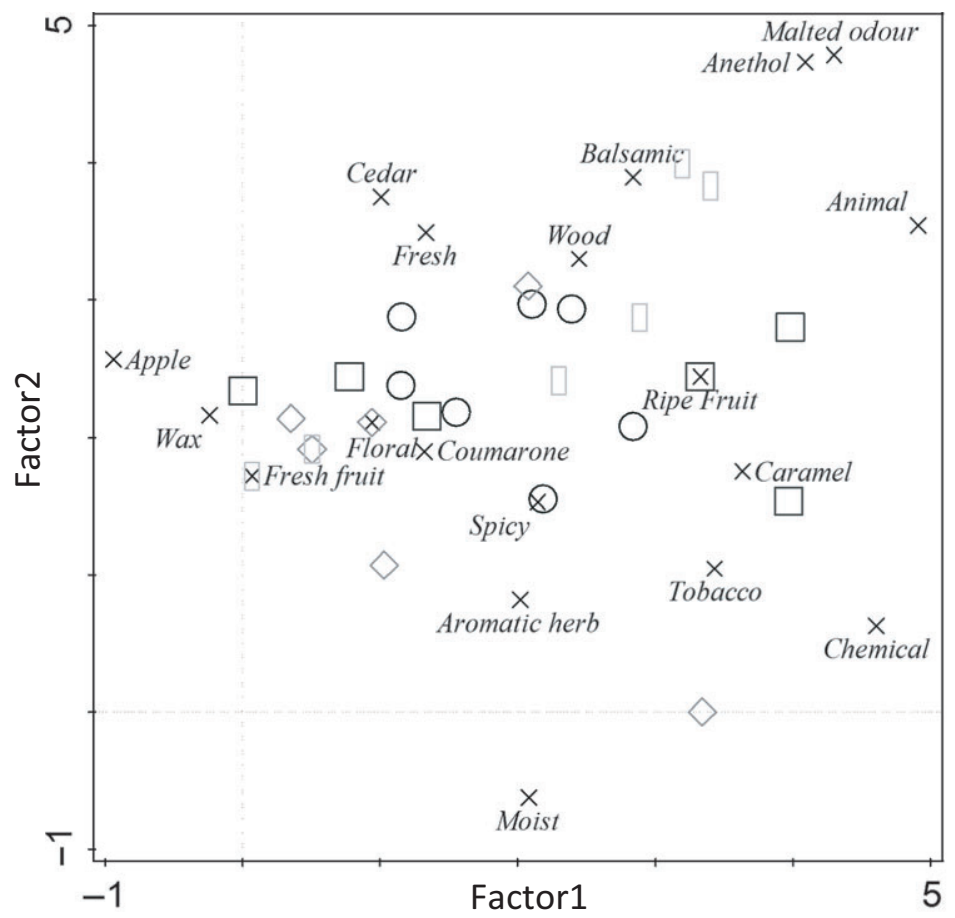

Samples
Patagonian Forest $\square$ Espinal $\diamond$ Pampa $\square$ Parana Delta and Islands

Figure 2 CA-biplot of aroma descriptors of Argentinean honey samples from different ecoregions. honeys from different regions $(P>0.05)$ (Table 1$)$. Melibiose and raffinose were only found in one sample and were discarded form the statistical analysis. The amount of sucrose is a very important parameter in evaluating the maturity, early harvest or adulteration of honeys (da Silva et al., 2016). In the honey samples analysed, the sucrose content was lower than $1.5 \mathrm{~g} /$ $100 \mathrm{~g}$, which is adequate according to the Codex Alimentarius (Bogdanov et al., 1999).

The trisaccharides melezitose and raffinose are considered to be indicators of honeydew honey. Samples from Patagonian Forest presented the highest amount of melezitose $(P \leq 0.05)$ (Table 1$)$, but raffinose was only found in one simple and in a low content $(2.3 \mathrm{~g} /$ $100 \mathrm{~g})$. Moreover, in the present work, most of the honey samples from Patagonian Forest ecoregion showed a low value of electrical conductivity which may correspond to blossom honey $\left(\leq 0.8 \mathrm{mS} \mathrm{cm}^{-1}\right)$ (Table S2) (Bogdanov et al., 1999). Besides, the melissopalynology analysis showed that honeydew elements were scarce.

\section{Sensory characteristics}

To achieve a good representation of sensory characteristics, a PCA was performed (Fig. 1). PC1, PC2 and PC3 showed eigenvalues $>1$ were considered in the analysis. But only the first two contained $>20 \%$ of the explained variation (Table S3). Therefore, the interpretation of the PCA was limited to the first two axes (Peltier et al., 2015) which explained the $63.5 \%$ of the total variance. As indicated in Fig. 1, samples from Pampa could be characterised by high values of crystallisation.

Different studies have provided information on the relationship between the main sugars in honeys (fructose and glucose) and moisture with its crystallisation tendency. It is widely accepted that the ratio of fructose/glucose indicates the ability of honey to crystallise, as the glucose is less soluble in water than fructose (El Sohaimy et al., 2015). However, it has been indicated that the glucose/moisture ratio could be a better indicator than the fructose/glucose ratio for the prediction of honey crystallisation (El Sohaimy et al., 2015). According to Manikis \& Thrasivoulou (2001), honey generally crystalises fast when this ratio is $\geq 2.1$. In the present work, in all the Argentinean honeys analysed, this ratio was lower than 2.1. Therefore, it could be concluded that none of the studied samples had a tendency to fast crystallisation. On the other hand, significant correlations were found between the HMF content and the granularity of honey samples $(P \leq 0.05)$; moreover, the size of the crystals in honey samples was significantly correlated 
with the diastase activity $(P \leq 0.05)$ (Table 2$)$. Diastase activity and HMF content are considered indicators of ageing and/or overheating of honey samples, as the enzyme activity decreases while the HMF increases in these conditions (Machado De-Melo et al., 2017). Hence, it could be considered that the crystallisation of honey samples was determined mainly by the storage conditions of the samples (time and temperature), as samples with high levels of HMF and low levels of diastase activity presented the highest crystals size and granularity. In good agreement with these results, Lupano (2007) indicated that the crystal size of honey increases with the storage time, while the storage temperature affects the crystallisation degree and the crystal size.

Colour intensity determined by the trained panel was significantly correlated with the Pfund colour $(r=0.86$, $P \leq 0.05)$. Besides, significant correlations $(P \leq 0.05)$ were found between the colour intensity and the fluency and the crystallisation of honey samples $(r=0.51$ and $r$ $=-0.4$, respectively) (Table 2 ). This indicates that honeys with lower crystallisation and higher fluency were perceived as darker by the panellists.

\section{Aroma evaluation}

In the present work, a total of 19 aroma descriptors were found in honey samples (Table S2). A CA was performed to determine the relationships among the different honey production regions and the attributes of the samples (Fig. 2). This analysis showed that two factors accounted for $24 \%$ of the variability of the data. Similar explained variance results were found in sensory analysis with nontrained and trained panellists (Veramendi et al., 2013; Kostov et al., 2014). This low proportion is expected considering the complexity in the odour sample profile, besides when CA is used to analyse a sorting task, it could underestimate the proportion of explained variance (Veramendi et al., 2013). Rinnan et al. (2015) have indicate that, although CA is by far the most common analytical tool applied in this type of response data, the model does not contain any information regarding the uncertainty in the different attributes (which accounts for a large part of the data variation). Therefore, the multivariate data analysis efficiently separates the information from the noise associated with the uncertainty. But, as the noisy part of the data is large, the explained variation could seem to be rather low. However, it is important to notice that CA explains the part of the data which holds the information of interest (Rinnan et al., 2015).

Figure 2 shows the projection of the attributes and the samples in a factorial plane obtained by the CA. According to the distribution of attributes in the plane, it can be seen that floral, fresh fruit and coumarone aromas were associated. These terms were

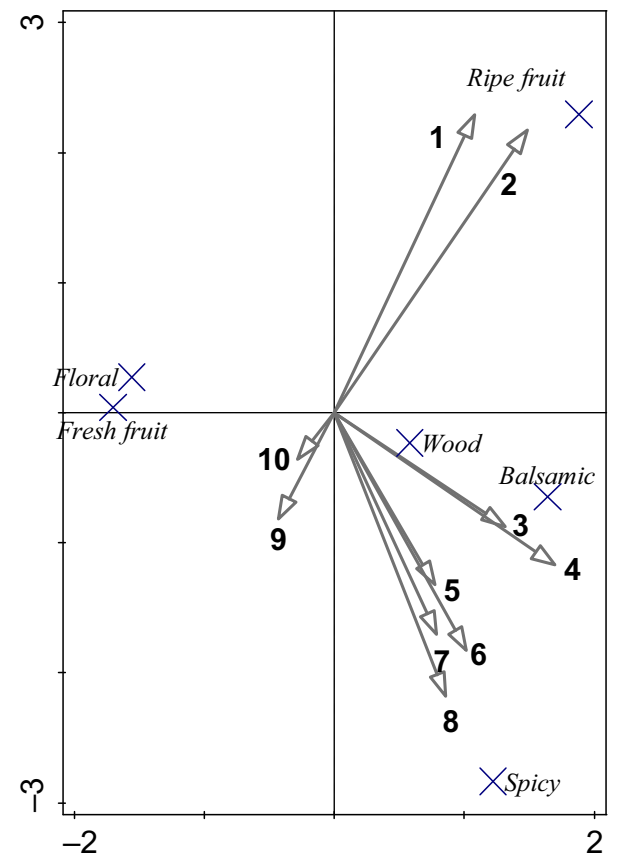

Figure 3 CCA-biplot of response variables (aroma descriptors: Ripe fruit; Wood, Balsamic; Spicy; Floral and Fresh Fruit) and the selected explanatory variables (volatile compounds): 1 ethyl phenylacetate; 2 ethyl octanoate; 3 acetophenone; 4 unknown compound (m/z: 57,85,128); 5 3-methyloctane; 6: 2-ethylhexan-1-ol; 7 dimethyl2-methylenebicyclo[2.2.1] heptan-3-one; 8: terpineol; 9: benzaldehyde; 10: myrtenal.

mentioned with similar frequency for several samples, so they are situated near the coordinate centre (Orjuela-Palacio et al., 2014). However, some samples from Pampa, Espinal and Parana Delta and Islands ecoregions could be better related to aromas such as anethole, balsamic, malted odour, moist, chemical and animal.

\section{Correlation between aroma descriptors and volatile compounds}

Volatile and semi-volatile compounds in honey determine its aroma. In the present work, a total of 110 volatile compounds were determined in the samples analysed (data not shown). However, not all volatile compounds have a significant contribution to honey aroma (Siegmund et al., 2017). Therefore, only volatile compounds that showed a significant effect on the honey aroma were considered $(P \leq 0.05)$.

CCA was used to analyse correlations between the volatile compounds found in honey and their most frequent aroma descriptors: ripe fruit, wood, balsamic, spicy, floral and fresh fruit. A total of ten compounds were found to be significantly correlated with these aromas $(P \leq 0.05)$ : ethyl octanoate $(P=0.0004)$; 
unknown compound (m/z: 57,85,128) $(P=0.0027)$; myrtenal $(P=0.0024)$, terpineol $(P=0.015)$, acetophenone $\quad(P=0.0162) ; \quad$ 2-ethylhexan-1-ol $\quad(P=0.0185)$, ethyl phenylacetate $(P=0.0358)$, dimethyl-2-methylenebicyclo[2.2.1]heptan-3-one $(P=0.0446)$; benzaldehyde $\quad(P=0.0478) ; \quad 3$-methyloctane $\quad(P=0.0492)$ (Table S4). The production region did not have any significant effect on the aroma of honey samples $(P>0.05)$. Moreover, a significant correlation between honey aroma descriptors and the selected volatile compounds was found $(P=0.001)$. Therefore, it could be concluded that the chosen volatile compounds had a significant effect on the aroma description of honey samples. The CCA-biplot can be seen in Fig. 3; the first two factors (F1, F2) account for $67.72 \%$ of the explained fitted variation.

Esters are odour-active compounds that might contribute to characteristic smells of fruits and flowers (Tian et al., 2016). As illustrated in Fig. 3, the esters ethyl phenylacetate and ethyl octanoate were significantly correlated with ripe fruit aroma in honey. In good agreement with this result, it has been indicated that esters could be well associated with fruity aroma notes and with sweet, strawberry, raspberry juice aroma in buckwheat honey (Wardencki et al., 2009).

Acetophenone has been described in honey from different floral origins, including Taraxacum officinale, Robinia pseudoacacia, Brassica napus, Castanea sativa and Lavandula angustifolia (Siegmund et al., 2017). According to the present results, acetophenone and unknown compound (m/z: $\underline{57}, 85,128)$ were strongly linked to wood and balsamic odours. Castro-Vázquez et al. (2012) also found significant correlations between these descriptors and volatile compounds during honey storage at different temperatures. These authors found that some compounds (such as 3-dihydro-3,5-dihydroxy-6-methyl-4(H)-pyran-4-one, p-anisaldehyde and 2-furanmethanol) were also significantly correlated with both: balsamic and wood odours.

Furthermore, 3-methyloctane, 2-ethylhexan-1-ol, dimethyl-2-methylenebicyclo[2.2.1]heptan-3-one and terpineol were strongly linked to the spicy odour perception (Fig. 3). In line with this finding, CastroVázquez et al. (2007) also indicated that terpineol was an odour-active compound and it could be described as a 'green' aroma.

As explained before, floral and fresh fruit aromas were associated and mentioned with similar frequency for several samples. Therefore, these descriptors are close together (Fig. 3). Besides, it could be concluded that these aromas were associated with the presence of myrtenal and benzaldehyde. Although benzaldehyde has been often been associated with sweet, almond and marzipan aroma (Manyi-Loh et al., 2011), in agreement with our results, it has also been indicated that it might contribute to the fruity aroma of honeys determined by sensory analysis (Tian et al., 2016). Also in line with our findings, investigations performed in Baccharis uncinella essential oil indicated that myrtenal presents a floral aroma (Xavier et al., 2017).

The association between the aroma of honey samples and their botanical origin was also analysed by CCA. Only clover honeys showed a significant correlation with the aroma descriptors of the samples analysed $(P=0.012)$. According to the present results, clover honeys showed a 'floral aroma' (CCA $P$-value $=$ 0.01) (data not shown). Further work should be done with a higher number of monofloral honeys to confirm this hypothesis. Nonetheless, Ciappini et al. (2013) have already indicated that clover honeys from Pampeana region (Argentina) could be characterised as a subtle fruity and floral aroma.

\section{Conclusions}

In the present work, honeys from different ecoregions of Argentina were analysed, and the correlations between their sensory and physicochemical parameters were evaluated in detail.

Results support the idea that the granularity and crystal size of honeys with similar crystallisation tendency (glucose/water ratio $<2.1$ ) are determined only by their storage conditions. Besides, it could be confirmed that honeys with lower crystallisation and higher fluency score were perceived as darker by the assessors.

CCA can successfully be used to find correlations between volatile compounds in honeys and their aroma descriptors. In the Argentinean honeys analysed, ethyl phenylacetate and ethyl octanoate were significantly correlated with ripe fruit aroma. Acetophenone and an unknown compound (m/z: $57,85,128)$ were strongly linked to wood and balsamic odours. Besides, 3-methyloctane, 2-ethylhexan-1-ol, dimethyl-2-methylenebicyclo [2.2.1]heptan-3-one and terpineol contributed to the spicy odour. Finally, it was found that floral and fresh fruit aromas were associated with the presence of myrtenal and benzaldehyde.

\section{Acknowledgments}

These experiments were financially supported by CONICET (PIP 0480) and Universidad Nacional de La Plata, Argentina.

\section{References}

Belay, A., Solomon, W.K., Bultossa, G., Adgaba, N. \& Melaku, S. (2015). Botanical origin, colour, granulation, and sensory properties of the Harenna forest honey, Bale, Ethiopia. Food Chemistry, 167, 213-219.

Bogdanov, S. (2002). Harmonized Methods of International Honey Commission. Liebefeld, Bern, Switzerland: FAM. 
Bogdanov, S., Lüllmann, C., Martin, P. et al. (1999). Honey quality and international regulatory standards: review by the International Honey Commission. Bee World, 80, 61-69.

Boufadi, Y.M., Soubhye, J., Nève, J., Van Antwerpen, P. \& Riazi, A. (2016). Antimicrobial effects of six Algerian propolis extracts. International Journal of Food Science \& Technology, 51, 2613-2620.

Braak, C.J.F. \& Šmilauer, P. (2012). CANOCO Reference Manual and User's Guide: Software for Ordination (Version 5.0). New York: Biometris. Wageningen University and Research Centre.

Brščić, K., Šugar, T. \& Poljuha, D. (2017). An empirical examination of consumer preferences for honey in Croatia. Applied Economics, 49, 5877-5889.

Castiglioni, S., Stefano, M., Astolfi, P. \& Carloni, P. (2017). Chemometric approach to the analysis of antioxidant properties and colour of typical Italian monofloral honeys. International Journal of Food Science \& Technology, 52, 1138-1146.

Castro-Vázquez, L., Díaz-Maroto, M.C. \& Pérez-Coello, M.S. (2007). Aroma composition and new chemical markers of Spanish citrus honeys. Food Chemistry, 103, 601-606.

Castro-Vázquez, L., Alañon, M.E., Gonzalez-Viñas, M.A. \& Pérez-Coello, M.S. (2012). Changes in the volatile fractions and sensory properties of heather honey during storage under different temperatures. European Food Research and Technology, 235, 185-193.

Ciappini, M.C., Di Vito, M.V., Gatti, M.B. \& Calviño, A.M. (2013). Development of a quantitative descriptive sensory honey analysis: application to eucalyptus and clover honeys. Advance Journal of Food Science and Technology, 5, 829-838.

Ciappini, M., Vitelleschi, M. \& Calviño, A. (2016). Chemometrics classification of argentine clover and eucalyptus honeys according to palynological, physicochemical, and sensory properties. International Journal of Food Properties, 19, 111-123.

El Sohaimy, S.A., Masry, S.H.D. \& Shehata, M.G. (2015). Physicochemical characteristics of honey from different origins. Annals of Agricultural Sciences, 60, 279-287.

Fagúndez, G.A. \& Caccavari, M.A. (2006). Pollen analysis of honeys from the central zone of the Argentine province of Entre Ríos. Grana, 45, 305-320.

Forcone, A. (2008). Pollen analysis of honey from Chubut (Argentinean Patagonia). Grana, 47, 147-158.

Grane, A. \& Jach, A. (2014). Applications of principal component analysis (PCA) in food science and technology. In: Mathematical and Statistical Methods in Food Science and Technology (edited by D. Granato \& G. Ares). Pp. 57-87. Chichester, UK: John Wiley \& Sons.

IRAM. (1995). Instituto Argentino de Normalización y Certificación, 2002. Análisis Sensorial - Directivas generales para la metodología.

IRAM. (1996). Instituto Argentino de Normalización y Certificación, 20005-1 Análisis sensorial-Guía general para la selección, entrenamiento y seguimiento de los evaluadores.

IRAM. (2014). Instituto Argentino de Normalización y Certificación, 15980-1 Análisis sensorial-Guía general para establecer el perfil sensorial.

Kostov, B., Bécue-Bertaut, M. \& Husson, F. (2014). An original methodology for the analysis and interpretation of word-count based methods: multiple factor analysis for contingency tables complemented by consensual words. Food Quality and Preference, 32, 35-40.

Lichtenberg-Kraag, B. (2014). Evidence for correlation between invertase activity and sucrose content during the ripening process of honey. Journal of Apicultural Research, 53, 364-373.

Louveaux, J., Maurizio, A. \& Vorhwhol, G. (1978). Methods of melissopalynology by international commission for bee botany of IUBS. Bee World, 59, 139-157.

Lupano, C.E. (2007). Crystallisation of honey. In: Functional Properties of Food Components (edited by C.E. Lupano). Pp. 109-123. Kerala, India: Research Signpost.
Machado De-Melo, A.A., Almeida-Muradian, L.B., Sancho, M.T. \& Pascual-Maté, A. (2017). Composition and properties of Apis mellifera honey: a review. Journal of Apicultural Research, https:// doi.org/10.1080/00218839.2017.1338444.

Manikis, I. \& Thrasivoulou, A. (2001). The relation of physicochemical characteristics of honey and the crystallization sensitive parameters. Apiacta, 36, 106-112.

Manyi-Loh, C.E., Ndip, R.N. \& Clarke, A.M. (2011). Volatile compounds in honey: a review on their involvement in aroma, botanical origin determination and potential biomedical activities. International Journal of Molecular Sciences, 12, 9514-9532.

Orjuela-Palacio, J.M., Zamora, M.C. \& Lanari, M.C. (2014). Consumers' acceptance of a high-polyphenol yerba mate/black currant beverage: effect of repeated tasting. Food Research International, 57, 26-33.

Patrignani, M., Bernardelli, C., Conforti, P.A. et al. (2015). Geographical discrimination of honeys through antioxidant capacity, mineral content and colour. International Journal of Food Science \& Technology, 50, 2598-2605.

Peltier, C., Visalli, M. \& Schlich, P. (2015). Comparison of canonical variate analysis and principal component analysis on 422 descriptive sensory studies. Food Quality and Preference, 40, 326-333.

Piana, M.L., Oddo, L.P., Bentabol, A., Bruneau, E., Bogdanov, S. \& Declerck, C.G. (2004). Sensory analysis applied to honey: state of the art. Apidologie, 35, S26-S37.

Rinnan, A., Giacalone, D. \& Frøst, M.B. (2015). Check-all-thatapply data analysed by Partial Least Squares regression. Food Quality and Preference, 42, 146-153.

Schüttler, A., Friedel, M., Jung, R., Rauhut, D. \& Darriet, P. (2015). Characterizing aromatic typicality of Riesling wines: merging volatile compositional and sensory aspects. Food Research International, 69, 26-37.

Siegmund, B., Urdl, K., Jurek, A. \& Leitner, E. (2017). "More than Honey": investigation on volatiles from monovarietal honeys using new analytical and sensory approaches. Journal of Agricultural and Food Chemistry, https://doi.org/10.1021/acs.jafc.6b05009.

Silva, P., Freitas, J., Silva, C.L., Perestrelo, R., Nunes, F.M. \& Câmara, J.S. (2017). Establishment of authenticity and typicality of sugarcane honey based on volatile profile and multivariate analysis. Food Control, 73, 1176-1188.

da Silva, P.M., Gauche, C., Gonzaga, L.V., Costa, A.C.O. \& Fett, R. (2016). Honey: chemical composition, stability and authenticity. Food Chemistry, 196, 309-323.

Tananaki, C., Thrasyvoulou, A., Giraudel, J.L. \& Montury, M. (2007). Determination of volatile characteristics of Greek and Turkish pine honey samples and their classification by using Kohonen self-organising maps. Food Chemistry, 101, 1687-1693.

Tian, H., Shen, Y., Yu, H. \& Chen, C. (2016). Aroma features of honey measured by sensory evaluation, gas chromatography-mass spectrometry and electronic nose. International Journal of Food Properties, https://doi.org/10.1080/10942912.2016.1213744.

Truzzi, C., Illuminati, S., Annibaldia, A., Finale, C., Rossetti, M. \& Scarponi, G. (2014). Physicochemical properties of honey from Marche, Central Italy: classification of unifloral and multifloral honeys by multivariate analysis. Natural Product Communications, 9, 1595-1602.

Valentin, D., Chollet, S., Lelievre, M. \& Abdi, H. (2012). Quick and dirty but still pretty good: a review of new descriptive methods in food science. International Journal of Food Science \& Technology, 47, 1563-1578.

Veramendi, M., Herencia, P. \& Ares, G. (2013). Perfume odor categorization: to what extent trained assessors and consumers agree? Journal of Sensory Studies, 28, 76-89.

Wardencki, W., Chmiel, T., Dymerski, T., Biernacka, P. \& Plutowska, B. (2009). Application of gas chromatography, mass spectrometry and olfactometry for quality assessment of selected food products. Ecological Chemistry and Engineering, 16, 287-300. 
Xavier, V.B., Minteguiaga, M., Umpiérrez, N., Vargas, R.M., Dellacassa, E. \& Cassel, E. (2017). Olfactometry evaluation and antimicrobial analysis of essential oils from Baccharis dentata (Vell.) GM Barroso and Baccharis uncinella DC. Journal of Essential Oil Research, 29, 137-144.

Zhao, L., Qi, S., Liang, X. et al. (2017). Determination and distribution of biogenic amines in bee pollen. International Journal of Food Science \& Technology, https://doi.org/10.1111/ijfs.13570.

\section{Supporting Information}

Additional Supporting Information may be found in the online version of this article:

Figure S1. Argentinean ecoregions where the honey samples were harvested in 2014.
Table S1. Olfactory descriptors used in aroma evaluation. Assessors had to indicate the family or subfamily to which the odour belongs and its distinguished notes whenever possible.

Table S2. Physicochemical parameters, aroma descriptors and botanical origin of Argentinean honeys from different ecoregions

Table S3. Eigenvalues, cumulative variance and loadings of the variables for the first three principal components (PC).

Table S4. Volatile compounds significantly associated to honey aroma, tentatively identified in samples. 